\title{
Mobilidade urbana de crianças: agenda de pesquisa e possibilidades de análise*
}

\author{
Children's urban mobility: research agenda and possibilities for analysis
}

\section{Movilidad urbana de niños/as: agenda de investigação y posibilidades de análisis}

\author{
FERNANDA MÜLLER**
}

\begin{abstract}
RESUMO
O artigo apresenta uma agenda de pesquisa em andamento sobre a mobilidade urbana de crianças em Brasília (DF). A mobilidade urbana de crianças que residem em Regiões Administrativas do Distrito Federal diferentes daquela onde estudam foi tratada tomando-se como campo uma escola-classe do Plano Piloto. O desenho metodológico compreendeu a sessão de um curta-metragem seguido de um debate, a realização de um desenho e uma entrevista individual com cada criança. Possibilitou acessar experiências de 243 crianças de pré-escola e Ensino Fundamental/ Anos Iniciais. Os dados gerados permitiram uma análise sobre os modais e itinerários realizados, pessoas que acompanham as crianças nos percursos e interações. A mobilidade das crianças é bem mais complexa do que sugerem as pesquisas quantitativas de origem/destino. Combinações de modais, arranjos com parentes e amigos e outras estratégias de acomodação das necessidades de transporte das crianças são bastante frequentes.
\end{abstract}

Palavras-chave: Brasília (DF). Cidade. Infância. Mobilidade.

\begin{abstract}
This article presents an ongoing research agenda on children's urban mobility in Brasilia (DF). The research object, the urban mobility of children residing in Administrative Regions of the Federal District different from the one where they study, considered a Plano Piloto school-class as a research field. From a methodological design that comprised the session of a short film followed by a debate, a drawing, and an individual interview, it was possible to access experiences of 243 children who attend pre-school and Elementary School. The data generated allowed an analysis of the transport modals; routes; people who accompany children on the course; and interactions. Preliminary conclusions suggest that the reality of children's mobility is much more complex than quantitative origin/destination research suggests. Combinations of modals, arrangements with relatives and friends, and other strategies for accommodating children's transportation needs are quite frequent.
\end{abstract}

Keywords: Brasília (DF). City. Childhood. Mobility.

\section{RESUMEN}

El artículo presenta una agenda de investigación en marcha sobre la movilidad urbana de niños en Brasilia (DF). La movilidad urbana de niños que residen en Regiones Administrativas del Distrito Federal diferentes de aquella donde estudian fue tratada tomando como campo una escuela-clase del Plano Piloto. El diseño metodológico comprendió la sesión de un cortometraje seguido de un debate, la realización de un dibujo y una entrevista individual con cada niño/a. Posibilitó acceder a experiencias de 243 niños de preescolar y primaria. Los datos generados permitieron un análisis sobre los modales utilizados, itinerarios realizados, personas que acompañan a los niños en los recorridos e interacciones. La movilidad de los niños es mucho más compleja de lo que sugieren las investigaciones cuantitativas de origen/destino. Combinaciones de modales, arreglos con parientes y amigos y otras estrategias de acomodación de las necesidades de transporte de los niños son bastante frecuentes.

Palabras clave: Brasília (DF). Ciudad. Infancia. Movilidad.

\footnotetext{
*A autora agradece às agências de fomento Conselho Nacional de Desenvolvimento Científico e Tecnológico (CNPq) e Fundação de Empreendimentos Científicos e Tecnológicos (Finatec) pelos auxílios financeiros que têm possibilitado a realização da pesquisa e de seus subprojetos. É igualmente grata à colaboração de Anna Carolina de Souza Feitoza.

**Professora Associada da Universidade de Brasília e coordenadora do Grupo Interdisciplinar de Pesquisa sobre a Infância (GIPI). < http://orcid.org/00000002-1788-8662>. E-mail: fernandamuller@unb.br
} 


\section{INTRODUÇÃO}

Despender longos períodos no trânsito é uma constante para os habitantes das metrópoles brasileiras, e, não raramente, associam-se os sofrimentos da vida contemporânea aos adultos. São eles que aparecem nas reportagens de televisão passando horas imóveis nos seus carros em engarrafamentos ou, ainda, dependendo de duas ou três linhas de ônibus em viagens da periferia até os centros urbanos. Todavia, não se despreza esse fenômeno social, pelo contrário, aqui ele é estendido para um grupo ainda pouco estudado em sua relação com a cidade: as crianças. ${ }^{1}$

Partindo-se da premissa de que crianças também se deslocam em uma base diária nos médios e grandes centros urbanos, iniciou-se um estudo sobre a sua mobilidade no Distrito Federal, centrado especificamente na mobilidade de crianças pobres, que se deslocam de suas Regiões Administrativas periféricas para estudar no Plano Piloto ${ }^{2}$ de Brasília. O trabalho de campo foi iniciado em uma escolaclasse pública ${ }^{3}$ da Asa Norte do Plano Piloto. Ao longo dos anos, crianças dessas regiões ao norte do Distrito Federal têm frequentado essa escola-classe, substituindo o perfil majoritário dos usuários para quem a instituição foi originalmente planejada, ou seja, as crianças moradoras das superquadras ${ }^{4}$ da Asa Norte. Isso gerou novas desigualdades, imprevistas no planejamento urbano da cidade, que - como se vê mais adiante - se mostram na questão específica da mobilidade urbana das crianças.

$\mathrm{O}$ fenômeno da mobilidade urbana de crianças tem sido amplamente estudado em países de alta renda, sobretudo com foco nos impactos de programas de transporte voltados às crianças. Na Nova Zelândia, por exemplo, o ônibus escolar a pé ${ }^{5}$ (Walking School Buses - WSB) foi estudado de forma longitudinal (COLLINS; KEARNS,

\footnotetext{
1 A assertiva se baseia em uma comparação com estudos realizados sobre a relação de jovens e adultos com a cidade. Ainda que não haja aqui a intenção de listar os trabalhos nacionais e internacionais sobre infância e cidade, reconhece-se que a temática tem sido muito seriamente tratada e é um campo em pleno desenvolvimento no Brasil (MÜLLER; NUNES, 2014).

2 De acordo com o Iphan (BRASIL, 2015), a cidade-capital Brasília, que foi construída no território do Distrito Federal, acabou sendo reconhecida como o próprio Plano Piloto, nomenclatura dada ao projeto urbanístico de Lúcio Costa. O Eixo Rodoviário atravessa o Plano Piloto no sentido norte-sul (Asa Norte e Asa Sul) e o Eixo Monumental percorre a cidade no sentido leste-oeste.

3 Os conceitos de escola-classe e de escola-parque foram elaborados pelo educador Anísio Teixeira, que teve importância crucial no projeto de educação pública da nova capital do Brasil (SOUZA, 2016). As escolasclasse de Brasília, tendo sido a primeira implantada em 1957, foram inspiradas no projeto do Centro Popular de Educação Carneiro Ribeiro, do Estado da Bahia. As escolas-classe eram voltadas ao desenvolvimento de conteúdos curriculares, enquanto, nas escolas-parque, as pedagogias focavam a prática de oficinas, artes e esporte (CORDEIRO, 2001).

4 Superquadra é a forma de organização urbanística das Asas Norte e Sul do Plano Piloto de Brasília. Lúcio Costa (1990, p. 30) a define como “[...] uma sequência contínua de grandes quadras dispostas, em ordem dupla ou singela, de ambos os lados da faixa rodoviária $[\ldots$. ".".

5 Trata-se de um programa de vizinhança que envolve pais e mães voluntários que se encarregam de encontrar grupos de crianças e levá-los (e buscá-los) a pé até a escola.
}

2009). Estudos na Itália (RISSOTTO; TONUCCI, 2002; ALPARONE; PACILLI, 2012) e na Finlândia (KYTTÄ, 2004; KULLMAN, 2010) mostraram o quanto a cidade e as interações nela estabelecidas precisam ser consideradas para garantir a mobilidade independente de crianças. Em Londres, Jones et al. (2012) avaliaram a experiência de crianças em ônibus de linha, enfatizando que elas são socialmente ativas e que merecem ser estudadas.

Sabbag, Kuhnen e Vieira (2015) realizaram uma revisão bibliográfica internacional sobre mobilidade de crianças. Os autores mostram que o tema vem sendo tratado preponderantemente em estudos europeus, que sugerem "[...] a diminuição da liberdade e da mobilidade independente das crianças e seus efeitos para o desenvolvimento infantil, tais como a diminuição da autonomia, do livre trânsito e a dificuldade de reconhecimento do espaço geográfico da cidade pela criança" (SABBAG; KUHNEN; VIEIRA, 2015, p. 439). O Brasil ainda não conta com um repertório vasto de estudos específicos sobre mobilidade urbana de crianças ${ }^{6}$ (SABBAG; KUHNEN; VIEIRA, 2015).

$\mathrm{O}$ presente artigo tem um objetivo geral: apresentar uma agenda de pesquisa em andamento e conclusões preliminares sobre a circulação de um grupo de crianças no Distrito Federal. Por meio desse exercício serão apresentados outros subprojetos em curso, procedimentos metodológicos adotados e recortes de análise. Especificamente, e de forma mais intensa, o estudo pretende explorar os dados gerados com as crianças no trabalho de campo inicial, que começou pela escola-classe.

\section{DF, Brasília e Plano Piloto \& CIDADES-SATÉLITE}

Brasília foi planejada e construída para substituir a cidade do Rio de Janeiro como capital do Brasil. Lúcio Costa ganhou o concurso do Plano Piloto da nova capital, que foi inaugurada em 1960. Ainda que grandes expectativas tenham sido depositadas em Brasília, rapidamente ela passou a sofrer dos mesmos problemas urbanos relacionados com as desigualdades sociais encontradas em outras cidades brasileiras (MÜLLER; FARIAS, 2016).

Nunes (2010, p. 70) afirma que, embora reconhecido pelo seu caráter inovador, o projeto de Lúcio Costa pode ser criticado por ter causado três efeitos sociais: 1) "desaparecimento da rua, barreiras simbólicas nas superquadras gerando indefinições entre o espaço público e o espaço privado"; 2) "altíssimos custos de manutenção"; e 3) "perda qualitativa nos processos cotidianos de intera-

\footnotetext{
${ }^{6}$ Citam-se aqui três estudos sobre mobilidade urbana realizados recentemente em cidades brasileiras: Dutra (2013); Müller e Arruda (2013); e Cordeiro (2016).
} 
ção social urbana, consolidando uma cidade elitista e exclusiva". Esse aspecto exclusivista do Plano Piloto, que ainda é confundido com a própria Brasília, mas que se tornou a primeira Região Administrativa em 1989, pode ser explicado também pela política restritiva de ocupação do solo.

O projeto urbanístico de Lúcio Costa (1990, p.30) previu a construção das superquadras de "[...] gabarito máximo uniforme, talvez seis pavimentos e pilotis, e separação do tráfego de veículos do trânsito de pedestres, mormente o acesso à escola primária e às comodidades existentes no interior de cada quadra". Assim, o Plano Piloto conta atualmente com 117 superquadras, 1.392 edifícios, com altura entre quatro e seis andares (AMORIM; FLORES, 2005).

De fato, não era esperado que a população pobre, especialmente os candangos - denominação dada aos trabalhadores que construíram Brasília -, permanecesse na capital; posteriormente, essa população foi acomodada em cidades periféricas, com infraestrutura ainda precária. Paviani (1998, p.49) explica que a própria construção de Brasília foi "[...] um projeto, não explícito, de exclusão sócioespacial da população pobre, antes mesmo de sua inauguração". Ao encontro dessa tese, Nunes e Costa (2007, p. 53) sintetizam: “A monopolização do nome 'Brasília' pelo Plano Piloto e o tratamento secundário pelos formuladores da política urbana para os demais sítios do Distrito Federal pode ser explicada pela lógica segregacionista".

Logo, de acordo com Nunes e Costa (2007, p. 52), duas lógicas coexistem: "[...] de um lado, um plano piloto (Brasília) vitrine do urbanismo modernista, de outro, a expansão da área ocupada, através da criação de cidades satélites". Cidade-satélite é um termo que, do ponto de vista oficial, não mais existe. Ao longo de sua história, um tanto recente, o Distrito Federal foi subdividido em 31 Regiões Administrativas (RAs) e não em municípios.
Contudo, o termo cidade-satélite, como um lugar de pertencimento ou de exclusão, ainda é socialmente utilizado e reconhecido.

Com o passar do tempo, fatores demográficos e de renda passaram a modificar o uso das superquadras do Plano Piloto. Originalmente planejadas para satisfazer as necessidades dos moradores e garantir a educação formal de crianças, já não mais cumpre plenamente esse papel. No que diz respeito à educação, crianças de classe média e média alta geralmente frequentam escolas particulares, que ocupam áreas fora das superquadras, e também têm se envolvido cada vez mais em atividades extracurriculares. A preocupação original do projeto da capital era: “[...] a) distribuir equitativa e equidistantemente as escolas no Plano-Piloto e Cidades-Satélites, de modo que a criança percorresse o menor trajeto possível para atingir a escola, sem interferência do tráfego de veículos, para a comodidade e tranquilidade de pais e alunos" (SOUZA, 2016, p.46-47). Por outro lado, as escolas-classe e as escolas-parque passaram a atender não só as crianças moradoras das superquadras, mas também crianças de outras RAs. Certamente, isso ampliou a circulação de uma outra população no espaço urbano do Plano Piloto.

As pesquisas de origem/destino de caráter amostral que incluem a mobilidade de crianças são ainda bastante restritas. No caso do Distrito Federal, a Pesquisa Metropolitana por Amostra de Domicílios (PMAD), realizada pela Companhia de Planejamento do Distrito Federal (Codeplan) - GDF, 2013 -, gerou os dados de local de moradia e de estudo de crianças de todas as idades. Considerando a faixa etária de 0 a 12 anos, 336.949 crianças moram em outras Regiões Administrativas que não a do Plano Piloto; dessas, 17.800 se deslocam para estudar no Plano Piloto, o que perfaz uma população de $5,2 \%$ de crianças em circulação diária ${ }^{7}$ (Gráfico 1).

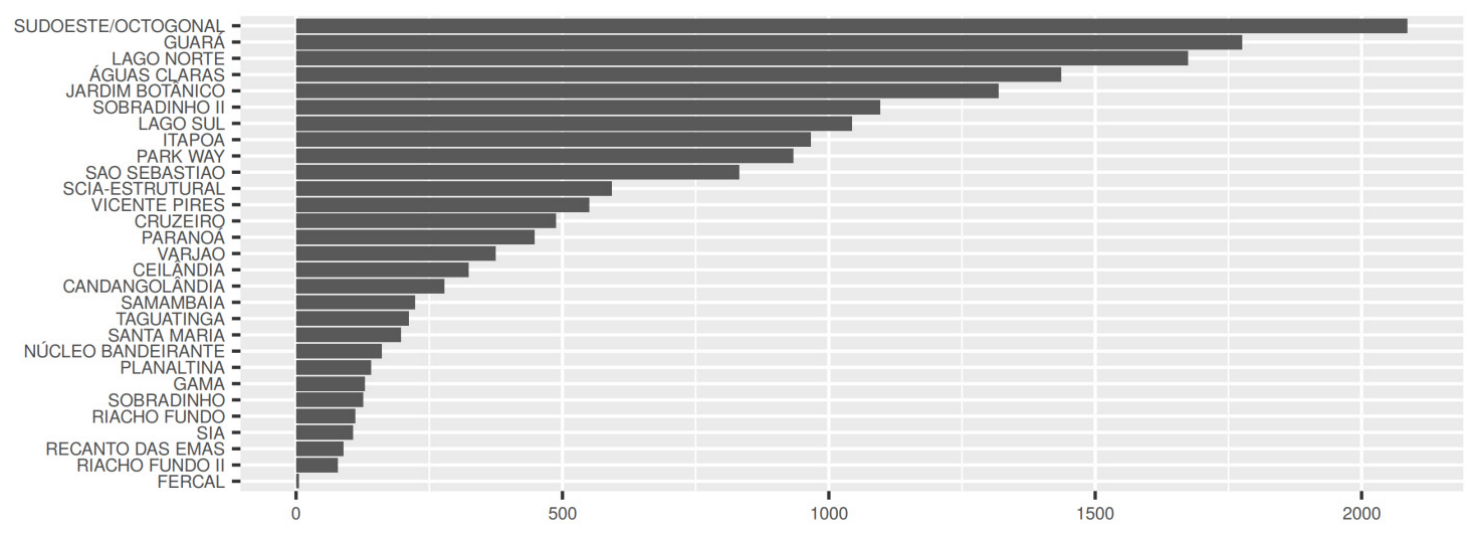

Gráfico 1. Número de crianças residentes nas RAs periféricas e que estudam no Plano Piloto Fonte: Elaboração própria com base em Codeplan (GDF, 2013).

\footnotetext{
Não se apresentam aqui dados de mobilidade de crianças que circulam em outras Regiões Administrativas. O argumento é construído com base nos dados de circulação de crianças para o Plano Piloto.
} 
Uma possível análise da PMAD (GDF, 2013), no entanto, encontra limites relacionados com a própria natureza quantitativa dos dados. Isto é, apenas informa as RAs em que as crianças residem e estudam e não apresenta dados sobre os modais utilizados, tempo de viagem e tampouco sobre quem as acompanha nesses deslocamentos. Igualmente importante: não se sabe o que as crianças fazem enquanto percorrem os trajetos. O baixo grau de detalhamento e a ênfase nos dados quantitativos restringem uma documentação detalhada sobre a experiência das crianças.

Essa lacuna nos protocolos de pesquisa de caráter censitário ou amostral - tipos de pesquisa igualmente importante para se acessar um panorama mais amplo das condições de vida das crianças - motivou o desenho do trabalho de campo inicial, que teve início na escola-classe. Essa escola recebe aproximadamente $50 \%$ de crianças de outras RAs, que não a do Plano Piloto. Igualmente, foi colocado em questão o caráter pendular sugerido pelas pesquisas de origem/destino, que assumem que crianças vêm e voltam da escola linearmente. Os procedimentos metodológicos são descritos na próxima seção.

\section{MOBILIDADE URBANA DE Crianças para o Plano Piloto: ESCOLHAS METODOLÓGICAS}

Um estudo realizado pela Secretaria de Estado de Mobilidade Urbana do Governo do Distrito Federal (GDF, 2016) demonstra que, considerando a população economicamente ativa, $64 \%$ trabalham em uma RA diferente daquela em que residem. Esse estudo também mostra que $43 \%$ trabalham no Plano Piloto. Considerando os deslocamentos diários dessa população adulta, o Distrito Federal contou, em 2015, com uma frota de mais de 1,2 milhão de automóveis, o que resulta na mais alta taxa de motorização do Brasil, com 41 automóveis por 100 habitantes (DENATRAN, 2017). Em relação ao total de deslocamentos, aproximadamente $45 \%$ são executados em veículos individuais motorizados; $32 \%$ em transporte coletivo motorizado; e $21 \%$ em transporte não motorizado (GDF, 2016).

Do ponto de vista qualitativo, a rede de transporte público do Distrito Federal está longe de ser exemplar (CARVALHO, 2008). Frequentes greves, interrupções e problemas técnicos tornam o sistema pouco confiável. $\mathrm{Se}$, em situações do cotidiano, uma percentagem da população apela para o uso de vans e táxis ilegais, em períodos de greve de motoristas de ônibus, por exemplo, esses serviços se fazem disponíveis a um custo que pode oscilar consideravelmente (CARVALHO, 2008; GDF 2013). Nunes (2010, p. 71) argumenta que "Temos entre a cidade planejada e a cidade 'espontânea' dinâmicas de uso e ocupação do solo, e, portanto, de práticas de interação distintas e às vezes simultâneas". A afirmação do autor pode ser igualmente aplicada à mobilidade urbana.

No Distrito Federal, crianças se beneficiam da Lei no 4.462 (GDF, 2010), que dispõe sobre o Passe Livre Estudantil nas modalidades de transporte público coletivo. A lei favorece todas as crianças de 0 a 5 anos, que se beneficiam da gratuidade do transporte, e todos os estudantes de educação básica e ensino superior, de escolas públicas ou privadas, de zonas urbanas ou rurais, que residem ou fazem estágio obrigatório a mais de um quilômetro da instituição em que estão matriculados. Esses estudantes têm direito ao Passe Livre Estudantil, que tinha 200 mil beneficiados no início de 2016 (GDF, 2016).

Outro programa refere-se ao benefício do ônibus escolar, ${ }^{8}$ que é financiado pelo governo federal. O Distrito Federal conta com 550 ônibus, com capacidade de 45 lugares, contratados por licitação; possui também 106 veículos adquiridos por meio do programa Caminho da Escola (FNDE), os quais têm capacidade mínima de 13 e máxima de 55 lugares (TRIBUNAL DE CONTAS DO DISTRITO FEDERAL, 2016).

Com o objetivo de mapear experiências de um grupo de crianças que se desloca diariamente para o Plano Piloto, considerou-se a escola-classe como campo. A instituição atende crianças de educação infantil (pré-escola) e anos iniciais do ensino fundamental ( 10 ao $5^{\circ}$ ano). São sete turmas pela manhã, no período das $7 \mathrm{~h} 30 \mathrm{~min}$ às $12 \mathrm{~h} 30 \mathrm{~min}$, e sete turmas à tarde, no período das $13 \mathrm{~h}$ às $18 \mathrm{~h}$. Totalizam assim 14 turmas e aproximadamente 240 crianças.

Os objetivo e a metodologia de pesquisa estiveram em compasso para compreender a experiência de mobilidade de crianças a partir da sua própria perspectiva. Mais do que isso, assim como em outras pesquisas que se propuseram a investigar crianças por elas próprias (vide CHRISTENSEN et al., 2011; MÜLLER, 2007; RAMOS, 2014; SALGADO, BIRCKNELL e PATIÑO, 2014; FARIAS e MÜLLER, 2016, dentre outros), elementos lúdicos foram considerados para tratar de um tema associado ao uso do espaço. Não necessariamente o espaço urbano é entendido, vivenciado, usado por crianças e pela pesquisadora, uma adulta, da mesma forma.

O trabalho seguiu três etapas, que contemplaram encontros coletivos e individuais com as crianças. Primeiramente, foi iniciado um debate, em cada uma das 14 turmas, cujo tema era mobilidade. Essa conversa inicial foi catalisada com a sessão do filme de animação de curtametragem $A$ ilha (2008). Por meio de uma linguagem

\footnotetext{
8 O Ministério da Educação (MEC) desenvolve dois programas relacionados com o transporte escolar: Caminho da Escola e Programa Nacional de Apoio ao Transporte do Escolar (PNATE), com foco no atendimento de alunos da zona rural.
} 
fundamentada sobretudo na imagem, e não na fala, e em elementos lúdicos que se mostraram apelativos às crianças, o curta trata de uma situação de total isolamento da personagem principal provocada pelo tráfego maciço de carros em uma metrópole. Especificamente, apresenta uma narrativa linear dividida em três momentos, quais sejam: a) uma rápida apresentação da personagem, mas que já favorece a empatia do espectador; b) o problema, que transporta a personagem para a "ilha", um pequeno espaço seguro perdido em um "oceano" de carros em movimento incessante; c) a solução do problema: um deus ex-machina que desce do céu e faz brotar da terra um semáforo e surgir uma faixa de segurança. Por fim, os carros param e o herói se liberta de sua reclusão.

Em um segundo momento, as crianças desenharam diferentes trajetos que enfrentam diariamente nos percursos casa-escola e escola-casa. Esse recurso, o do desenho, foi pensado com o objetivo de ampliar as possibilidades de comunicação entre crianças e pesquisadora e entre crianças, já que foi realizado individualmente, mas na companhia de pares. Igualmente, está demonstrado na literatura que, por meio do desenho, crianças se expressam de uma forma rica e peculiar (KOSMINSKY, 1998; GOBBI, 1999; WIGGERS, 2003; PIRES, 2007; SOUSA, 2015, dentre outros), que combina símbolo e significado.

Por fim, em um terceiro momento, o desenho foi tomado como um recurso de elicitação de informações ${ }^{9}$ acerca da mobilidade de cada criança. Uma conversa infor- mal foi conduzida tomando o desenho como referência. Nessa fase, o objetivo centrou-se em mapear meios de transporte utilizados na vinda para a escola e na volta para casa; itinerários, companhias; e, sobretudo, interações estabelecidas nesses percursos. Foram 243 crianças entrevistadas, que compartilharam experiências bastante diversas e de forma precisa e detalhada. As seções subsequentes analisam esse mapeamento realizado com as 243 crianças.

\section{ESTRATÉGIAS DE MOBILIDADE DAS CRIANÇAS}

Os Gráficos 2 e $\mathbf{3}$ sintetizam as informações relacionadas com o modal utilizado pelas crianças. Optou-se por apresentar dois gráficos separados, isto é, um com as informações sobre o transporte de ida para a escola, e o outro sobre a volta para casa, pois identificou-se que, das 243 crianças, 26 usam modais diferentes nesses percursos. Tanto no Gráfico $\mathbf{2}$ como no Gráfico 3, foi possível demonstrar o tipo de modal associado a cada RA.

Como mostra o Gráfico 2, para vir para a escola, 124 crianças são trazidas de carro; 86 dependem de van/ ônibus escolar; 17 utilizam ônibus de linha; 15 crianças vêm a pé e somente uma criança vem de motocicleta. Considerando o número total de crianças, não há dúvidas de que o carro é o meio mais utilizado nesses trajetos. Contudo, uma aproximação mais qualitativa das experiências das crianças mostra que, dessas 124 usuárias

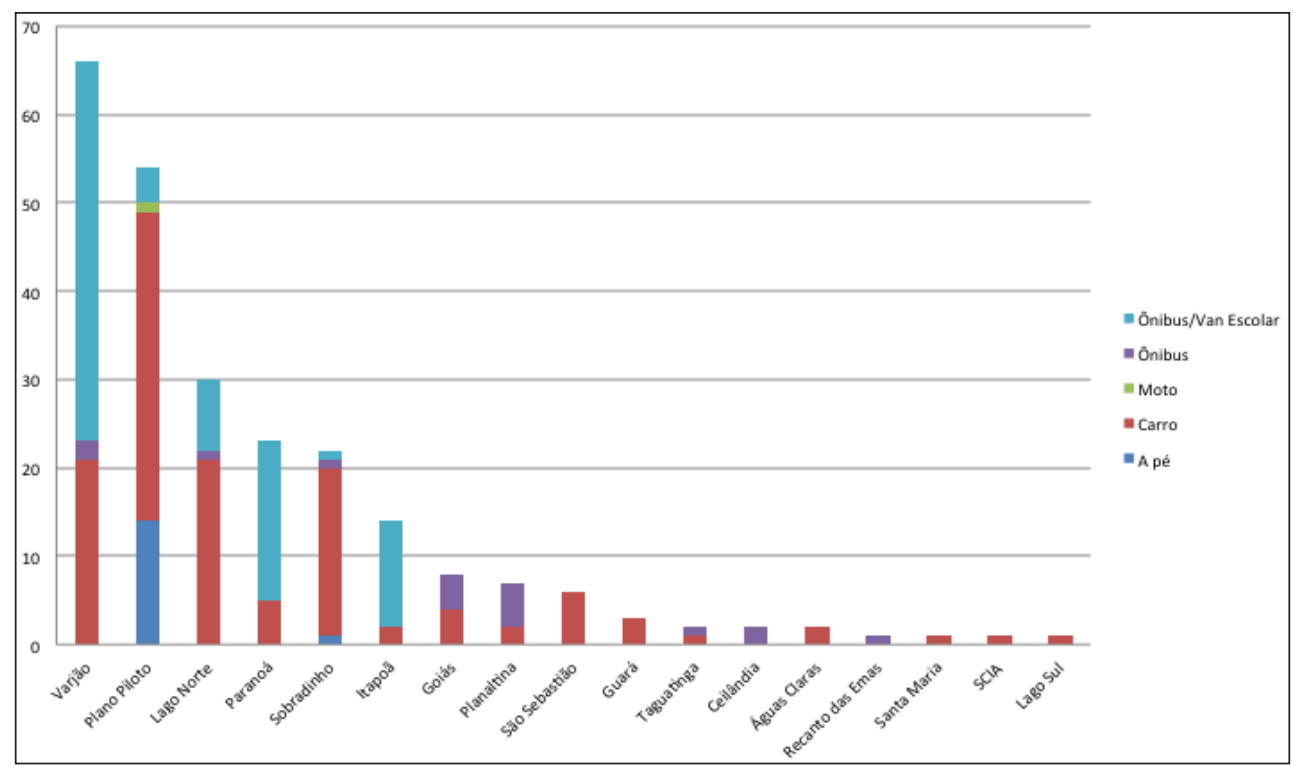

Gráfico 2. Modal utilizado na ida para a escola por Região Administrativa

Fonte: Pesquisa própria.

\footnotetext{
9 A consideração do desenho como técnica de elicitação tem inspiração em dois estudos que utilizaram outra linguagem comunicativa como catalisadora de uma conversa: a fotografia. Tanto Clark-Ibáñez (2004) quanto Mason e Tipper (2006) enfatizam as possibilidades da fotografia para facilitar a comunicação entre interlocutores e pesquisadores. As
}

últimas chamam essa abordagem de fotoelicitação. O desenho, no contexto da pesquisa aqui tratada, teve também o papel de deixar a criança com maior controle do que queria compartilhar com a pesquisadora. Importante também salientar que os desenhos das crianças estão sendo analisados em um subprojeto decorrente da pesquisa. 
de carro, 44 crianças possuem irmãos ou primos que estudam na escola e são conduzidas por seus pais ou tios. Também quatro crianças são trazidas de carro por vizinhos, que possuem um filho ou neto matriculado na escola e oferecem o transporte aos demais por um custo mensal.

O segundo modal mais utilizado é a van/ônibus escolar, que transporta 86 crianças. São 13 os motoristas mencionados pelas crianças, geralmente chamados por "tio" ou "tia"10, seguidos de seus nomes ou apelidos. Em geral, as crianças demonstraram apreço por eles, o que não foi percebido em relação a alguns monitores, isto é, auxiliares que abrem e fecham a porta da van, levam e buscam as crianças na entrada da escola e, mais importante, monitoram se as regras da van estão ou não sendo cumpridas.11 Com exceção de poucos ônibus escolares que conduzem crianças de zonais rurais das RAs, a maioria delas é transportada por vans/ônibus escolares mediante uma quantia paga mensalmente. Logo, a maioria das famílias de RAs externas à do Plano Piloto contrata um serviço de transporte coletivo privado, o que é justificado pelas crianças como uma opção dos pais para garantir pontualidade e segurança.

Também é interessante notar a predominância de certos meios de transporte nas RAs de origem das crianças. As crianças do Varjão e do Itapoã são preponderantemente transportadas de van/ônibus escolar. As crianças que moram no Plano Piloto, Lago Norte, Sobradinho, Guará, Águas Claras, Santa Maria, SCIA e Lago Sul são principalmente transportadas de carro. As do Paranoá, Planaltina e Recanto das Emas vêm, em sua maioria, de ônibus de linha. Das crianças dos municípios do Estado de Goiás e de Taguatinga, a metade vem de carro, e a outra metade de ônibus.

Uma questão interessante é que 30 crianças usam mais de um modal na ida para a escola, o que depende de diversos fatores: dia da semana (crianças cujos pais têm guarda compartilhada partem de casa e usam modais diferentes de acordo com os dias da semana); disponibilidade dos pais (aqueles que trabalham no Plano Piloto conduzem as crianças de carro em alguns dias, e outros parentes as levam de ônibus nos outros); atividades

\footnotetext{
${ }^{10} \mathrm{Na}$ escola da pesquisa, assim como em outras instituições privadas ou públicas de Educação Infantil e Ensino Fundamental (Anos Iniciais) do Distrito Federal, a professora costuma ser chamada de "tia". Este último caso, entretanto, não pode ser generalizado para todo o Distrito Federal ou para o Brasil.

${ }^{11}$ Outro subprojeto de pesquisa em andamento refere-se a uma etnografia no transporte escolar, mais precisamente um estudo que acompanha um grupo de crianças habitantes de uma das Regiões Administrativas periféricas do DF nos seus trajetos de ônibus escolar para a escolaclasse. Um recorte de análise desse subprojeto tem sido as pedagogias do transporte coletivo de crianças. Para isso, é dada uma especial ênfase à observação de interações sociais nos termos de Goffman $(1959,1963$, 1964, 1982).
}

extracurriculares (algumas crianças frequentam atividades esportivas durante a semana, o que interfere na escolha do modal). Também foram identificados casos em que a criança utiliza mais de um modal no trecho casa-escola. Aline, ${ }^{12}$ por exemplo, do $2^{2}$ ano matutino, mora em São Sebastião e vem para a escola com seu pai. Ambos contam com a carona de uma amiga da família. Eles partem de São Sebastião e são deixados em um ponto de ônibus em frente a uma escola privada localizada na Asa Norte do Plano Piloto. De lá tomam um ônibus, descem próximo à superquadra e andam até a escola-classe (Figura 1). A simulação abaixo é feita considerando todo o trajeto feito de carro, porque o Google Maps ${ }^{13}$ não permite uma busca com diferentes modais. Contudo, calculou-se que a viagem, considerando a primeira parte de carro e a segunda de ônibus, totaliza $1 \mathrm{~h} 06 \mathrm{~min}$.

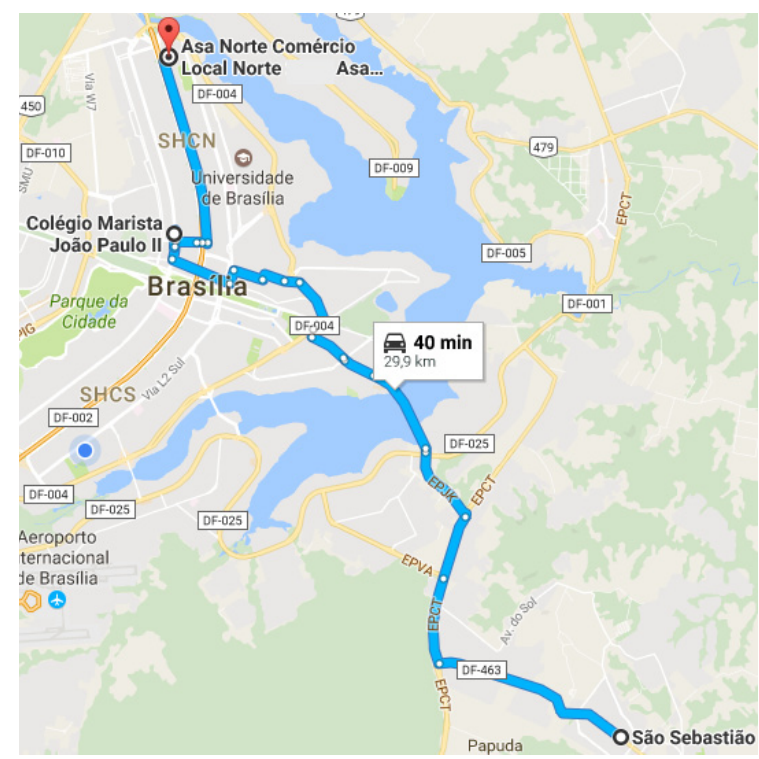

Figura 1. Trajeto de Aline na ida para a escola Fonte: Pesquisa da autora com base em Google Maps (2017).

No Gráfico 3, é possível perceber que, para voltar para casa, 109 crianças se deslocam de carro; 93 crianças dependem de van/ônibus escolar; 22 utilizam ônibus de linha; e 19 vão a pé. Ainda que haja diferença em relação ao percurso de ida para a escola, há similaridade com referência à análise do outro gráfico.

Igualmente como no percurso de vinda, 33 crianças usam mais de um modal na volta da escola. Por exemplo, Olavo, que estuda no $3^{\text {o }}$ ano matutino, utiliza, na volta

\footnotetext{
12 Todos os nomes são fictícios para preservar o anonimato das crianças.

13 As projeções do Google Maps não contam com os endereços das crianças, mas somente com a inserção da Região Administrativa; os endereços da escola-classe ou da superquadra não são exatos.
} 


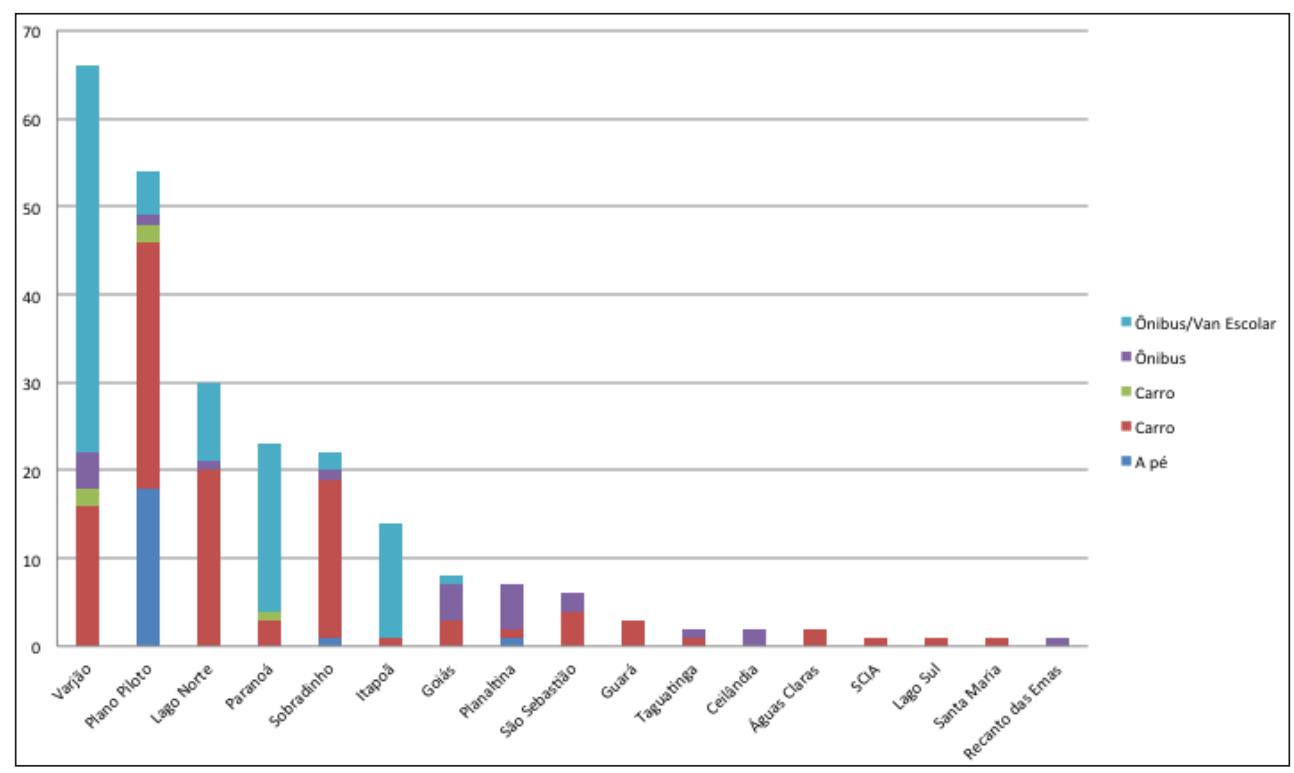

Gráfico 3. Modal utilizado na volta para casa por Região Administrativa Fonte: Pesquisa própria.

da escola, dois tipos de modal, o que depende do destino. Se for direto para a sua casa, que fica em Sobradinho, ele volta de van/ônibus escolar. Em alguns dias da semana, ele ainda vai de carro, com o pai, para a casa da avó, que mora na Asa Norte. Depois, usando o mesmo modal, ambos voltam para casa.

Em relação às pessoas que acompanham as crianças nos dois trajetos, foi possível mapear que a maioria vem e volta da escola com a mãe e/ou com o pai. Precisamente 134 crianças vêm para a escola e 120 voltam para casa com os pais. O modal pode variar nesse caso. Em segundo lugar, são os motoristas de van/ônibus escolar que conduzem 86 crianças na ida para a escola e 92 na volta para casa e, nesse caso, obviamente, o modal não varia. Em menor número, ainda há registro de vizinhos, avós, irmãos como acompanhantes das crianças; os modais, então, são carro e ônibus de linha. Algumas crianças vêm para a escola e voltam para a casa sozinhas - seis e nove, respectivamente; os modais utilizados são ônibus de linha e a pé.

A Tabela 1, adiante, sistematiza os dados referentes às RAs onde as crianças residem, a renda familiar per capita dessas regiões e a distância total que seria percorrida, se elas realizassem diretamente o percurso casa-escola. Considerou-se como modais tanto o ônibus quanto o carro para obter a estimativa de tempo de percurso. Ainda que a escola ofereça dois turnos de atividades, a estimativa foi feita tendo como referência o horário de chegada do turno da manhã, ou seja, 7h30min.

Apesar de não se contar com a renda per capita da família das crianças da pesquisa, o dado de renda média das RAs de residência sugere a disparidade de suas condições econômicas. O Varjão e o Plano Piloto são as RAs em que mais crianças residem; todavia, enquanto na primeira RA os moradores auferem pouco mais de $\mathrm{R} \$ 600,00$ por mês, na segunda, esse valor ultrapassa $\mathrm{R} \$$ $5.000,00$. Esse é só um exemplo das desigualdades sociais existentes entre as crianças.

Um outro ponto relevante é a comparação da estimativa de tempo de viagem de carro e de transporte público. $\mathrm{O}$ trajeto de ônibus de linha dura três a quatro vezes mais do que o de carro, com exceção do percurso feito pela única criança do Lago Sul que, se dependesse de ônibus, demoraria seis vezes mais (essa criança vem e volta da escola de carro).

Ainda uma outra questão de destaque refere-se à distância que as crianças dos municípios de Goiás percorrem. O Google Maps (2017) não estima trajetos interestaduais com transporte público. As próprias crianças que vivem nos municípios de Goiás e dependem de transporte coletivo informaram que utilizam ônibus semi-interestaduais, cuja linha conecta a sua cidade ao Plano Piloto; há também a possibilidade de baldeação, ou seja, de contar, primeiramente, com uma linha de ônibus até a fronteira do Distrito Federal e com outra linha até Goiás.

Ainda que as atuais tecnologias permitam chegar a um cálculo preciso das distâncias percorridas, considerando um ponto de partida e outro de chegada, a experiência de muitas crianças é muito mais complexa do que as projeções. Por exemplo, Nicolas estuda no 4 o ano vespertino e mora no Paranoá. Assim como esse menino, outras 85 crianças da escola dependem de van/ ônibus escolar e, de uma forma ou de outra, expuseram 
Tabela 1. Dados sintéticos sobre RAs e tempos de percurso

\begin{tabular}{|c|c|c|c|c|c|}
\hline Região Administrativa & $\begin{array}{c}\text { Renda per capita } \\
\text { (R\$) }\end{array}$ & $\begin{array}{l}\text { Número de } \\
\text { crianças }\end{array}$ & Distância em km & Tempo / carro & Tempo / ônibus \\
\hline Varjão & 627,81 & 66 & $7 \mathrm{~km}$ & $12 \mathrm{~min}$ & $47 \mathrm{~min}$ \\
\hline Plano Piloto* & $5.189,00$ & 54 & 5.5 & $10 \mathrm{~min}$ & $41 \mathrm{~min}$ \\
\hline Lago Norte & 4.700 & 30 & 8 & $12 \mathrm{~min}$ & $51 \mathrm{~min}$ \\
\hline Paranoá & 866,48 & 23 & 25 & $28 \mathrm{~min}$ & $2 \mathrm{~h}$ \\
\hline Sobradinho & $1.775,79$ & 22 & 18 & $26 \mathrm{~min}$ & $1 \mathrm{~h} 26 \mathrm{~min}$ \\
\hline Itapoã & 750,77 & 14 & 21.5 & $28 \mathrm{~min}$ & $1 \mathrm{~h} 43 \mathrm{~min}$ \\
\hline Planaltina & 933,80 & 07 & 38 & $40 \mathrm{~min}$ & $2 \mathrm{~h} 21 \mathrm{~min}$ \\
\hline São Sebastião & 985,18 & 06 & 28.5 & $30 \mathrm{~min}$ & $1 \mathrm{~h} 49 \mathrm{~min}$ \\
\hline Planaltina de Goiás & 382,50 & 04 & 52.3 & $1 \mathrm{~h} 20 \mathrm{~min}$ & $\mathrm{ND}^{* *}$ \\
\hline Guará & $2.683,23$ & 03 & 18.5 & $30 \mathrm{~min}$ & $1 \mathrm{~h} 25 \mathrm{~min}$ \\
\hline Águas Lindas de Goiás & 356,25 & 02 & 54.8 & $1 \mathrm{~h} 20 \mathrm{~min}$ & ND \\
\hline Valparaíso de Goiás & 510,00 & 02 & 44.2 & $1 \mathrm{~h} 25 \mathrm{~min}$ & ND \\
\hline Ceilândia & 604,00 & 02 & 35 & $45 \mathrm{~min}$ & $2 \mathrm{~h} 03 \mathrm{~min}$ \\
\hline Taguatinga & $1.639,04$ & 02 & 25.5 & $40 \mathrm{~min}$ & $1 \mathrm{~h} 55 \mathrm{~min}$ \\
\hline Águas Claras & 2.282 & 02 & 25 & $30 \mathrm{~min}$ & $2 \mathrm{~h} 05 \mathrm{~min}$ \\
\hline Recanto das Emas & 803,92 & 01 & 40 & $40 \mathrm{~min}$ & $2 \mathrm{~h} 28 \mathrm{~min}$ \\
\hline Santa Maria & 725,00 & 01 & 35.5 & $45 \mathrm{~min}$ & $2 \mathrm{~h} 14 \mathrm{~min}$ \\
\hline SCIA & 521,80 & 01 & 16 & $35 \mathrm{~min}$ & $1 \mathrm{~h} 34 \mathrm{~min}$ \\
\hline Lago Sul & $8.117,53$ & 01 & 14 & $22 \mathrm{~min}$ & $1 \mathrm{~h} 29 \mathrm{~min}$ \\
\hline
\end{tabular}

* Todas as crianças dessa categoria habitam a Asa Norte do Plano Piloto. Para fins de projeção, o endereço mais distante da escola foi tomado como referência.

** Abreviação de "não disponível", pois informações de trajetos intermunicipais não são geradas pelo Google Maps (2017).

Fonte: Pesquisa da autora com base em Codeplan (GDF, 2010, 2014), IBGE (2016) e Google Maps (2017).

percursos complexos de ida e de volta da escola, que não necessariamente coincidem com o tempo estimado. Se Nicolas viesse diretamente à escola, de van, o tempo despendido seria em média de $28 \mathrm{~min}$ em um trajeto de $25 \mathrm{~km}$, e este seria provavelmente o seu percurso (Figura 2).

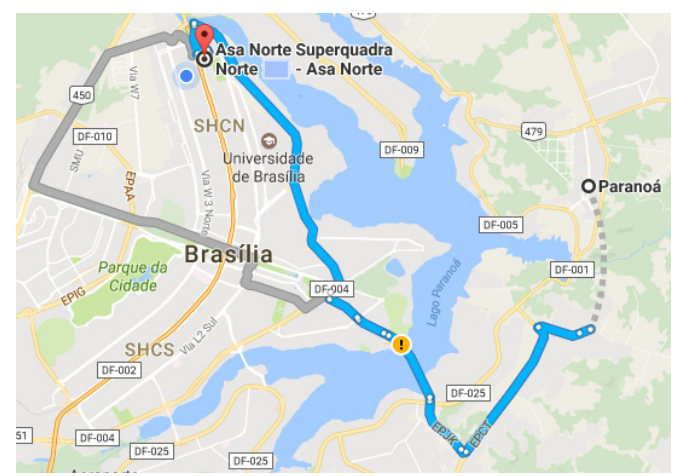

Figura 2. Trajeto do Paranoá para a Asa Norte do Plano Piloto

Fonte: Pesquisa da autora com base em Google Maps (2017).

Nicolas apresenta outra experiência. Ele sabe quando o "tio" da van chegou em sua casa pelo barulho: "A van é nova, o tio comprou este ano". Mas o auxiliar do motorista, o "monitor", ainda não se encontra na van e o menino assume a função de abrir a porta para outras crianças até o encontrarem no Paranoá. O itinerário dessa van percorre outras seis escolas, antes de chegar à de Nicolas. Assim, uma projeção mostra que, ao seguir um itinerário não linear, tanto de partida (sai do Paranoá para o Itapoã, antes de seguir para o Plano Piloto) quanto de percurso no próprio Plano Piloto, o tempo gasto seria $1 \mathrm{~h} 21 \mathrm{~min}$ em um trajeto de $52 \mathrm{~km}$. Entretanto, nessa estimativa, o tempo de permanência em cada escola para a condução de cada grupo de crianças e, portanto, de espera para as demais não é contabilizado. Tampouco o são certas atividades de socialização com os pares e com o espaço que, "de vez em quando", segundo Nicolas, são proporcionadas pelo "tio", que permite que as crianças colham mangas das árvores dos gramados públicos próximos a uma das escolas (Figura 3).

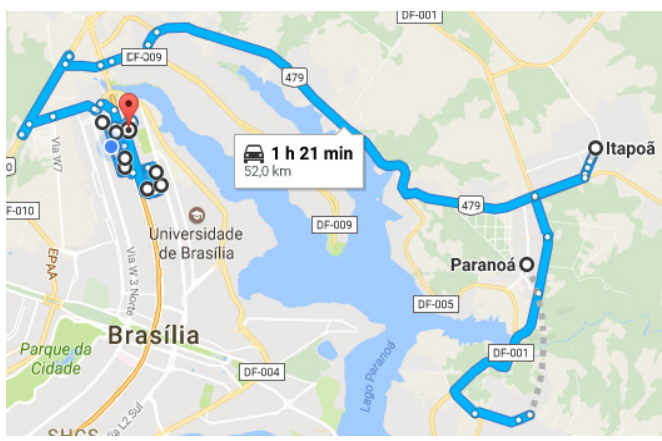

Figura 3. Deslocamento efetivo de Nicolas Fonte: Pesquisa da autora com base em Google Maps (2017). 
No caso de Nicolas, ele vem e volta de van escolar, com o mesmo motorista, percorrendo esse itinerário tanto na vinda para a escola quanto na volta para casa. Nesses percursos, Nicolas tem experiências que não só ocorrem na escola, mas também no contexto muito maior, que é o da cidade, e com crianças que não necessariamente moram na sua RA e estudam na sua escola.

Outras experiências, como a de Nina, mostram ainda outras complexidades que precisam ser consideradas quando se trata de mobilidade de crianças. Ela se encontra no $4^{\circ}$ ano matutino, mora em Taguatinga e também utiliza apenas um modal, contudo chama a atenção a extensão da sua rotina. Estuda no Plano Piloto porque a escola fica próxima aos dois empregos da mãe, que é cobradora de ônibus e diarista. Se Nina viesse para o Plano Piloto e voltasse para casa logo depois do turno escolar, gastaria aproximadamente $4 \mathrm{~h}$ nos dois trajetos (Figura 4).

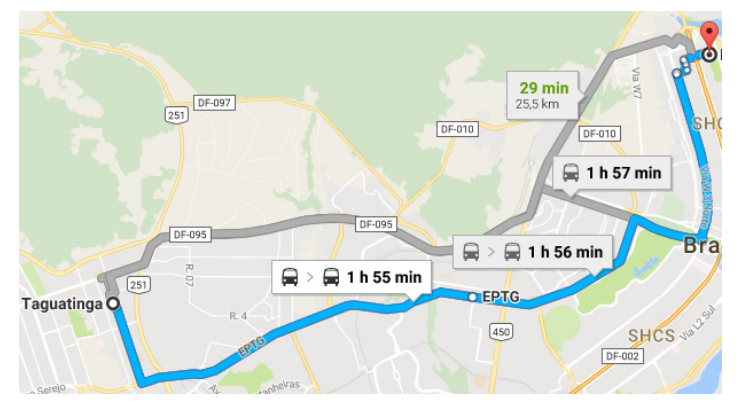

Figura 4. Trajeto de Taguatinga para a Asa Norte do Plano Piloto

Fonte: Pesquisa da autora com base em Google Maps (2017).

No entanto, a rotina semanal de Nina não funciona dessa maneira. Ela acorda todos os dias às $4 \mathrm{~h}$ da manhã, toma banho, veste o uniforme, escova o cabelo, coloca o lanche na mochila, toma café e, com a mãe, às $4 \mathrm{~h} 30 \mathrm{~min}$, desloca-se a pé de casa ao ponto de ônibus. Ainda é madrugada e está escuro. No ônibus, a menina por vezes brinca no telefone celular da mãe e lê livros, mas geralmente dorme. Elas optam pela linha de ônibus que faz o trajeto direto de Taguatinga para a L2 Norte. ${ }^{14}$

Quando esse ônibus específico se atrasa, elas apelam para linhas que fazem baldeação na Estrutural (RA XXVSCIA) ou na Rodoviária do Plano Piloto. No fim do turno escolar, a mãe a aguarda todos os dias na frente da escola. Juntas, caminham até o ponto, tomam um ônibus e dirigem-se a um apartamento, na Asa Norte, onde a mãe faz faxina diariamente. Lá, a menina almoça, assiste à televisão e faz seus deveres da escola. No meio da tarde, a mãe volta a trabalhar como cobradora de ônibus; Nina a acompanha. Depois de algumas viagens, ambas são

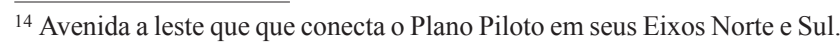

conduzidas, no próprio ônibus, até o Recanto das Emas, onde, às $19 \mathrm{~h}$, tomam uma outra condução para voltar para Taguatinga. Já é noite novamente. A mãe ainda prepara o jantar, as duas comem, conversam um pouco e vão dormir.

Desprezando o tempo que Nina permanece dentro do ônibus com a mãe, enquanto esta trabalha, o cálculo aproximado de duração de todos os itinerários, de ônibus, seria de $1 \mathrm{~h} 57 \mathrm{~min}$ (Taguatinga - escola-classe), somado a 28min (escola-classe - trabalho de diarista da mãe, na Asa Norte do Plano Piloto), mais 1h (Recanto das Emas - Taguatinga), o que totalizaria $3 \mathrm{~h} 25 \mathrm{~min}$ e $84 \mathrm{~km} \mathrm{de}$ deslocamento. Só para fins de representação, a figura a seguir mostra, sem considerar o percurso que faz enquanto a mãe está trabalhando, a amplitude dos deslocamentos diários de Nina (Figura 5).

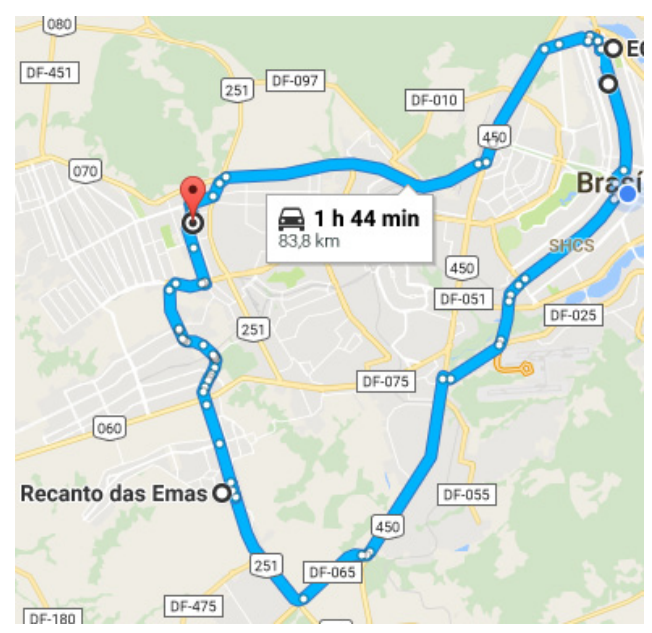

Figura 5. Deslocamento efetivo de Nina Fonte: Pesquisa da autora com base em Google Maps (2017).

\section{CONCLUSÕES PRELIMINARES}

Diferentemente de $A$ ilha, não há soluções mágicas para os problemas que as crianças enfrentam diariamente enquanto estão em trânsito para a escola ou para a casa. Para muitas, é comum acordar quando ainda não amanheceu; percorrer uma longa distância no ônibus; acompanhar a mãe ao trabalho; voltar sozinha para casa, com medo de algo imprevisível e perigoso ocorrer no ônibus. Essas situações não devem ser romantizadas ou somente tratadas como um tema de resiliência. As crianças sofrem imensamente com as desigualdades sociais que se mostram nas dificuldades diárias para chegar à escola e voltar dela

Uma questão que não pode ser desprezada é o descompasso entre as necessidades efetivas das crianças e o sistema de transporte público. Sobretudo para aquelas que dependem de ônibus de linha, seria necessário contemplar não só as necessidades dos adultos trabalhadores, mas também as das crianças que, igualmente, deslocam-se em 
uma base diária. Tal como sugere Tonucci (1997), esse seria um tema a ser tratado se a cidade fosse considerada um grande laboratório de experiências.

Por outro lado, após uma reflexão sobre os dados gerados na pesquisa, seria igualmente equivocado apresentar esses longos e complexos percursos das crianças como simples problemas a serem eliminados. Afinal, os problemas enfrentados nos trajetos diários também contam com soluções criativas, ora elaboradas pelas crianças, ora pensadas pelos adultos. Ambos lutam para exercer os seus direitos de estudar, trabalhar e circular, mesmo com toda sorte de entraves. Especialmente as crianças que se deslocam mais, ou seja, partindo das RAs mais periféricas, reconhecem que estudar no Plano Piloto é qualitativamente melhor do que nas suas regiões de origem. Esse investimento diário físico, emocional e também financeiro de crianças e de seus responsáveis não pode ser desprezado. Para compreender esse investimento, que, certamente, para alguns, beira o sacrifício, exige-se que pais, mães e demais parentes das crianças de RAs periféricas sejam também entrevistados. A necessidade de uma melhor compreensão do fenômeno da mobilidade de crianças para o Plano Piloto também tem a ver com uma pergunta não contemplada nas pesquisas origem/destino: por que as crianças se deslocam para o Plano Piloto? Obviamente, sabe-se que é para estudar, mas por que naquela escola, tão longe de casa? Por que não na própria RA de origem? Essas são questões que serão exploradas em outro trabalho.

A pesquisa indicou que a maioria das situações expostas pelas crianças desafiou o próprio princípio pelo qual as pesquisas de origem/destino de adultos e de crianças são realizadas, qual seja, o de que haveria um movimento pendular. Muitas crianças não vêm e voltam de casa da mesma forma, ou seja, utilizando o mesmo modal, acompanhadas pelas mesmas pessoas, ou percorrendo o mesmo caminho.

Diante do mapeamento apresentado neste artigo, muitos outros subprojetos foram elaborados e encontramse em fase de execução. Os próximos passos da agenda de pesquisa buscam exatamente aprofundar questões sobre pedagogias empregadas nas vans/ônibus escolares; interações estabelecidas pelas crianças nos mais diversos percursos; e o desenho como expressão de lógicas e estratégias de mobilidade na cidade.

\section{REFERÊNCIAS}

A ILHA. Direção: Alê Camargo. Distrito Federal, 2008. Disponível em: <http://portacurtas.org.br/filme/?name=a ilha8942> Acesso em: 20 ago. 2016.

ALPARONE, Francesca R.; PACILLI, Maria G. On children's independent mobility: the interplay of demographic, environmental, and psychosocial factors. Children's Geographies, v. 10, n. 1, p. 109-122, Feb. 2012. Disponível em: <http://dx.doi.org/10.1080/14733285.2011.638173>. Acesso em: 27 ago. 2017.

AMORIM, Cláudia. N.; FLORES, Alice L. Edifícios residenciais das superquadras do Plano Piloto, Brasília: aspectos de preservação e conforto ambiental. Brasília: FAU, Universidade de Brasília, 2005.

BARKER, John. Men and motors? Fathers' involvement in children's travel. Early Child Development and Care, v. 178, n. 7-8, p. 853-866, Oct./Dec. 2008. Disponível em: <http:// dx.doi.org/10.1080/03004430802352277>. Acesso em: 27 ago. 2017.

CAMARGO, Jean Carlos G. Os medos e os processos de segregação sócio-espacial na cidade de Brasília. In: ENCONTRO ANUAL DA ASSOCIAÇÃO NACIONAL DE PÓS-GRADUAÇÃO E PESQUISA EM CIÊNCIAS SOCIAIS (ANPOCS), 34, 2010, Caxambu. Anais... Caxambu: Anpocs, 2010. p. $1-30$

CARVALHO, Diego L. Mobilidade urbana e cidadania no Distrito Federal: um estudo do programa Brasília integrada, 2008, Dissertação (Mestrado em Sociologia) - Universidade de Brasília, Brasília, 2008.

CHRISTENSEN, Pia et al. Children, mobility and space: using GPS and mobile phone technologies in ethnographic rtesearch. Journal of Mixed Methods Research, v. 5, n. 3, p. 227-246, June 2011. Disponível em: <http://dx.doi org/10.1177/1558689811406121>. Acesso em: 27 ago. 2017

CLARK-IBÁÑEZ, Marisol. Framing the social world with photo-elicitation interviews. American Behavioral Scientist, v. 47, n. 12, p. 1507-1527, Aug. 2004. Disponível em: <http:// dx.doi.org/10.1177/0002764204266236>. Acesso em: 27 ago. 2017.

COLLINS, Damian; KEARNS, Robin A. Walking school buses in the Auckland region: a longitudinal assessment. Transport Policy, v. 17, n. 1, p. 1-8, Jan. 2010. Disponível em: <https:// doi.org/10.1016/j.tranpol.2009.06.003>. Acesso em: 27 ago. 2017.

CORDEIRO, Adriana T. Entre a casa e a escola: articulações discursivas em torno do transporte escolar privado. In: ENCONTRO DA ASSOCIAÇÃO NACIONAL DE PÓSGRADUAÇÃO E PESQUISA EM ADMINISTRAÇÃO (ANPAD), 40, 2016, Costa do Sauípe (Mata de São João/BA). Anais... Mata de São João/BA: Anpad, 2016. p. 1-16.

CORDEIRO, Célia M. F. Anísio Teixeira, uma "visão" do futuro. Estudos Avançados, v. 15, n. 42, p. 39-52, May/Aug. 2001. Disponível em: <http:/www.scielo.br/scielo.php?script=sci arttext\&pid=S0103-40142001000200012\&lng=en\&nrm=iso>. Acesso em: 27 ago. 2017.

COSTA, Lúcio. Relatório do Plano Piloto de Brasília. Brasília, 1991.

DEPARTAMENTO NACIONAL DE TRÂNSITO (DENATRAN). Frota de veículos, 2016. Disponível em: $<$ http://www.denatran. gov.br/index.php/estatistica/261-frota-2016>. Acesso em: jan. 2017.

DUTRA, Cristian P. R. "Andando" na cadeirinha: reflexões sobre as infâncias automobilizadas da Grande Florianópolis. 2013. Dissertação (Mestrado em Educação) - Universidade Federal de Santa Catarina, Florianópolis, 2013. 
FARIAS, Rhaisa N. P. Caderno de planejamento das atividades da turma do II Período. Distrito Federal, 2015 (mimeografado).

FARIAS, Rhaisa N. P.; MÜLLER, Fernanda. A cidade como espaço da infância. Educação \& Realidade, v. 42, n. 1, p. 261-282, jan./mar. 2016. Disponível em: <http://www.scielo.br/scielo. php?script=sci_arttext\&pid=S2175-62362017000100261\&lng =pt\&nrm=iso>. Acesso em: 27 ago. 2017.

GOBBI, Márcia A. Lápis vermelho é de mulherzinha? Relações de gênero, desenho infantil e crianças pequenas. Revista ProPosições, v. 10, n. 1, p. 169-193, mar. 1999. Disponível em: $<$ https://periodicos.sbu.unicamp.br/ojs/index.php/proposic/ article/view/8644106/11544>. Acesso em: 27 ago. 2017.

GOFFMAN, Erving. The presentation of self in everyday life. Garden City, N.Y.: Doubleday, 1959.

GOFFMAN, Erving. Behavior in public places: notes on the social organization of gatherings. New York: The Free Press, 1963.

GOFFMAN, Erving. The neglected situation. American Anthropologist, v. 66, n. 6, part 2, p. 133-136, 1964. Disponível em: <https://doi.org/10.1525/aa.1964.66.suppl_3.02a00090>. Acesso em: 27 ago. 2017.

GOFFMAN, Erving. Interaction ritual: essays on face-to-face behavior. New York, NY: Pantheon Books, 1982.

GOOGLE MAPS. Disponível em: <https://www.google.com/ maps>. Acesso em: jan. 2017.

GOVERNO DO DISTRITO FEDERAL (GDF). Distribuição de renda na Área Metropolitana Integrada de Brasília (Amib). Brasília, 2010. Disponível em: <http://www.bnb. gov.br/documents/88765/89729/6-distribuicao_renda_area metropolitana integrada brasilia amib.pdf/ca $27581 \mathrm{f}-811 \mathrm{~d}-$ 463e-8fdc-ed4 $\overline{\mathrm{d}} 54 \mathrm{dfed} 5 \mathrm{e}>$. Acesso em: nov. 2016.

GOVERNO DO DISTRITO FEDERAL (GDF). Lei no 4.462, de 13 de janeiro de 2010. Brasília, 2010. Disponível em: $<$ http://www.tc.df.gov.br/sinj/BaixarArquivoNorma.aspx?id file $=34 \mathrm{cc} 2619-7788-3596-\mathrm{a} 174-\mathrm{a} 41264 \mathrm{e} 494 \mathrm{~b} 1>$. Acesso em: nov. 2016.

GOVERNO DO DISTRITO FEDERAL (GDF). Evolução da fecundidade no Distrito Federal entre 2000 e 2010. Brasília, 2013. Disponível em: <http://www.codeplan.df.gov.br/areastematicas/demografia.html>. Acesso em: 13 nov. 2016.

GOVERNO DO DISTRITO FEDERAL (GDF). Pesquisa Metropolitana por Amostra de Domicílios (PMAD). Brasília, 2013. Disponível em: < http://www.codeplan.df.gov.br/areas-tematicas/ desenvolvimento-regional/pmad.html>. Acesso em: 20 abr. 2016.

GOVERNO DO DISTRITO FEDERAL (GDF). Síntese de informações socioeconômicas e geográficas. Brasília, 2014. Disponível em: <http:/www.codeplan.df.gov.br/images/ CODEPLAN/PDF/pesquisa_socioeconomica/df_em_sintese/ Sintese_de_Informacoes_Socioeconomicas_2014.pdf $>$. Acesso em: 4 nov. 2016.

GOVERNO DO DISTRITO FEDERAL (GDF). Programa de Mobilidade Urbana de Brasília. Brasília: 2016. Disponível em: $<$ http://editais.st.df.gov.br/programa/arquivos/apre_p.pdf>. Acesso em: 9 nov. 2016.

GOVERNO DO DISTRITO FEDERAL (GDF). Secretaria de Estado de Mobilidade Urbana. Brasília, 2016. Disponível em: http://www.semob.df.gov.br/. Acesso em: 2 dez. 2016.
INSTITUTO BRASILEIRO DE GEOGRAFIA E ESTATÍSTICA (IBGE). Estimativas populacionais para os municípios e para as Unidades da Federação brasileiros. Brasília, 2016. Disponível em: <http:/www.ibge.gov.br/home/estatistica/populacao/ estimativa2015/ estimativa_dou.shtm>. Acesso em: 10 jan. 2017.

INSTITUTO DO PATRIMÔNIO HISTÓRICO E ARTÍSTICO NACIONAL (IPHAN). Superquadra de Brasília: preservando um lugar de viver. Brasília, 2015.

JONES, Alasdair et al. Rethinking passive transport: bus fare exemptions and young people's wellbeing. Health \& Place, v. 18, p. 605-612, 2012. Disponível em: <https://doi.org/10.1016/ j.healthplace.2012.01.003>. Acesso em: 27 ago. 2017.

KOSMINSKY, Ethel V. Aqui é uma árvore, o Sol, a Lua. Aqui é um montão de guerra: o uso do desenho infantil em Sociologia. Cadernos Ceru, v. 9, p. 83-100, 1998.

KULLMAN, Kim. Transitional geographies: making mobile children. Social \& Cultural Geography, v. 11, n. 8, p. 829-846, dez. 2010. Disponível em: http://dx.doi.org/10.1080/14649365. 2010.523839. Acesso em: 27 ago. 2017.

KYTTÄ, Marketta. The extent of children's independent mobility and the number of actualized affordances as criteria for child-friendly environments. Journal of Environmental Psychology, v. 24, n. 2, p. 179-198, 2004. Disponível em: $<$ https://doi.org/10.1016/S0272-4944(03)00073-2>. Acesso em: 27 ago. 2017.

MASON, Jennifer; TIPPER, Becky. Children, kinship and creativity. University of Manchester, Morgan Centre, 2006 (Morgan Centre Working Papers, University of Manchester). Disponível em: <http://www.socialsciences.manchester.ac.uk/ morgancentre/research/childrens-kinship/2006-07-morganchildren-kinship.pdf>. Acesso em: 5 nov. 2017.

MÜLLER, Fernanda. Retratos da infância na cidade de Porto Alegre. 2007. Tese (Doutorado em Educação) - Universidade Federal do Rio Grande do Sul, Porto Alegre, 2007.

MÜLLER, Fernanda; NUNES, Brasilmar. F. Infância e cidade: um campo de estudo em desenvolvimento. Educação \& Sociedade, v. 35, n. 128, p. 659-674, jul./set. 2014. Disponível em: <http://dx.doi.org/10.1590/ES0101-73302014 35128129342>. Acesso em: 27 ago. 2017.

MÜLLER, Fernanda; FARIAS, Rhaisa N. Geographies of contemporary childhoods in Brasilia/Brazil. Papers Infancia_c, n. 15, p. 1-15, 2016. Disponível em: <http://www. infanciacontemporanea.com/wp-content/uploads/2016/11/ paper_ic_n15_mullerandpael.pdf>. Acesso em: 27 ago. 2017.

MÜLLER, Verônica R.; ARRUDA, Fabiana M. O trânsito e o transporte na cidade: caminhos propostos pelas crianças para uma maior mobilidade em Maringá/PR. Série-Estudos, v. 1, n. 35, p. 117-135, jan./jun. 2013. Disponível em: <http:// www.serie-estudos.ucdb.br/index.php/serie-estudos/article/ viewFile/23/318>. Acesso em: 27 ago. 2017.

NUNES, Brasilmar. Cidade vivida e cidade planejada: encontro da teoria com a pesquisa. Tomo, v. 16, p. 57-78, jan./jun. 2010. Disponível em: <http://dx.doi.org/10.21669/tomo.v0i16.519>. Acesso em: 27 ago. 2017.

NUNES, Brasilmar F.; COSTA, Arthur. Distrito Federal e Brasília: dinâmica urbana, violência e heterogeneidade social. 
Cadernos Metrópole (PUCSP), v. 17, p. 35-58, 1ํ sem. 2007. Disponível em: <http://dx.doi.org/10.1590/8762>. Acesso em: 27 ago. 2017.

PAVIANI, Aldo. A construção injusta do espaço urbano. In: PAVIANI, A. (Org.). A conquista da cidade. Brasília, DF: Universidade de Brasília, 1998. p.115-134.

PIRES, Flavia. Ser adulta e pesquisar crianças: explorando possibilidades metodológicas na pesquisa antropológica. Revista de Antropologia, v. 50, n. 1, p. 225-270, jan./jun. 2007. Disponível em: <http://www.scielo.br/scielo.php?script=sci arttext\&pid=S0034-77012007000100006\&lng=en\&nrm=iso>. Acesso em: 27 ago. 2017.

RAMOS, Anne Carolina. Sobre avós, netos e cidades: entrelaçando relações intergeracionais e experiências urbanas na infância. Educação \& Sociedade, v. 35, n. 128, p. 781-809, jul./set. 2014. Disponível em: <http://www.scielo.br/pdf/es/ v35n128/0101-7330-es-35-128-00781.pdf>. Acesso em: 27 ago. 2017.

RISSOTTO, Antonella.; TONUCCI, Francesco. Freedom of movement and environmental knowledge in elementary school children. Journal of Environmental Psychology, v. 22, n. 1-2, p. 65-77, 2002. Disponível em: <https://doi.org/10.1006/ jevp.2002.0243>. Acesso em: 27 ago. 2017.

SABBAG, Gabriela M.; KUHNEN, Ariane; VIEIRA, Mauro L. A mobilidade independente da criança em centros urbanos. Interações, Campo Grande, v. 16, n.2, p. 433-440, 2015. Disponível em: <http://www.scielo.br/scielo.php?script=sci arttext\&pid=S1518-70122015000200433\&lng=en\&nrm=iso>. Acesso em: 27 ago. 2017.

SALGADO, Marta M.; BICKNEL, David P.; GONZÁLEZPATIÑO, Javier. Del hogar a la ciudad como camino de ida y vuelta en el desarrollo de la identidad: el caso de las rutinas de la infancia urbana de clase media/alta en Madrid.
Educação \& Sociedade, v. 35, n. 128, p. 761-780, jul./set. 2014. Disponível em: <http://www.scielo.br/scielo.php?script=sci arttext\&pid=S0101-73302014000300761\&lng=en\&nrm=iso>. Acesso em: 27 ago. 2017.

SOUSA, Emilene L. As crianças e a etnografia: criatividade e imaginação na pesquisa de campo com crianças. Iluminuras, v. 16, n. 38, p. 140-164, jan./jul. 2015. Disponível em: <http:// seer.ufrgs.br/index.php/iluminuras/article/view/57434/34489>. Acesso em: 27 ago. 2017.

SOUZA, Edilson. Um plano educacional para um novo tempo: Anísio Teixeira e as escolas classe/escola parque de Brasília. Caderno Eletrônico de Ciências Sociais, Vitória, v. 3, n. 2, p. 39-52, 2016. Disponível em: http://periodicos.ufes.br/cadecs/ article/view/13654/9674. Acesso em: 27 ago. 2017.

TONUCCI, Francesco. La ciudad de los niños: un modo nuevo de pensar la ciudad. Madrid: Fundación Germán Sánchez Ruipérez, 1997.

TRIBUNAL DE CONTAS DO DISTRITO FEDERAL. Transporte escolar da rede pública de ensino do Distrito Federal. Brasília, 2016. Disponível em: <http://www.tc.df. gov.br/segecex/flip/sumarios/semag/transpesc/transpesc.pdf $>$. Acesso em: 8 nov. 2016.

WIGGERS, Ingrid Dittrich. Corpos desenhados: olhares de crianças de Brasília através da escola e da mídia. 2003. Tese (Doutorado em Educação) - Universidade de Santa Catarina, Florianópolis, 2003.

Recebido em 27.04.2018

Aprovado em 09.07.2018

Endereço para correspondência:

Universidade de Brasília (UnB)

Faculdade de Educação - Asa Norte 70910-900 Brasília, DF, Brasil 